\title{
ANALISIS SUARA PERNAPASAN PARU-PARU ASMA DENGAN TIDAK ASMA MENGGUNAKAN METODE K NEAREST NEIGHBORS
}

\section{Analysis Respiratory Lung Sounds of Asthma and Non-Asthma Using k Nearest Neighbors Method}

\author{
Ari Satriadi $^{[1]}$, I Made Budi Suksmadana ${ }^{[1]}$, Bulkis Kanata ${ }^{[1]}$ \\ ${ }^{1}$ Jurusan Teknik Elektro, Universitas Mataram. \\ Jln. Majapahit 62, Mataram, 83125 Lombok, Indonesia \\ Email: arisatriadi55@gmail.com
}

\begin{abstract}
ABSTRAK
Asma adalah penyakit pada saluran napas yang menyebabkan peningkatan hiperesponsif jalan napas dan menimbulkan gejala mengi/wheeze (napas berbunyi ngik-ngik). Bunyi napas wheeze merupakan salah satu ciri yang menandakan seseorang menderita asma. Penelitian ini dilakukan untuk membuat serta menguji suatu sistem yang dapat mengidentifikasi perbedaan ciri suara pernapasan wheeze pada pasien asma dan pernapasan lainnya dengan metode kNearest Neighbors (k-NN). Ciri suara yang digunakan yaitu rata-rata sinyal dan standar deviasi sinyal dalam domain waktu, rata-rata spektrum, standar deviasi spektrum, magnitude tertinggi saat frekuensi $0 \mathrm{~Hz}$, frekuensi dengan magnitude tertinggi pertama, kedua, dan ketiga. K-NN adalah sebuah metode untuk melakukan klasifikasi terhadap objek berdasarkan data pembelajaran yang jaraknya paling dekat dengan objek tersebut. Didapatkan data suara pernapasan wheeze dan non-wheeze melalui perekaman langsung kepada subjek penderita asma dan tidak asma. Dari seluruh data suara yang didapatkan kemudian dilakukan segmentasi data untuk mengambil event pernapasan yang dibutuhkan kemudian dilakukan ekstraksi ciri untuk mendapatkan ciri matematis dari suara tersebut. Delapan puluh persen dari total keseluruhan data dilakukan pelatihan menggunakan metode 10 fold cross validation dan didapatkan hasil pelatihan dengan kemampuan klasifikasi maksimum pada $\mathrm{k}=3$ dan $\mathrm{k}=5$ dengan validitas yang sama $97,2 \%$. Untuk pengujian kinerja k-NN pada tahap akhir diperoleh kemampuan maksimum pengklasifikasian untuk $\mathrm{k}=3$ adalah $86,6 \%$ dan $\mathrm{k}=5$ adalah $86,6 \%$.
\end{abstract}

Kata kunci: Asma, fold cross validation, wheeze.

\section{ABSTRACT}

Asthma is a disease in the respiratory tract that causes an increase hyperesponsiveness in the respiratory and causes wheeze symptoms. The sound of wheeze breath is one of the characteristics that indicate a person has asthma. This research was conducted to create and test a system that can identify differences in wheeze respiratory voice traits in asthma and other respiratory patients with the k-Nearest Neighbors (k-NN) method. The sound features used are the average signal and the standard deviation in the time domain, the average spectrum, the standard deviation of spectrum, the highest magnitude at $0 \mathrm{~Hz}$ frequency, the frequency with the highest magnitude first, second, and third. $k-N N$ is a method of classifying objects based on learning data closest to them. Obtained wheeze and non-wheeze respiratory voice data through live recording to subjects with asthma and not asthma. From all the sound data obtained then segmentation of the data to take the respiratory event needed then carried out the extraction of features to get the mathematical characteristics of the sound. $80 \%$ of the total data was conducted using the 10 fold cross validation method and was reviewed with maximum classification capabilities at $k=3$ and $k=5$ with the same validity of $97.2 \%$. For $k$-NN performance testing at the final stage obtained the maximum classification capability for $k=3$ is $86.6 \%$ and $k=5$ is $86.6 \%$.

Key words: Asthma, fold cross validation, wheeze. 


\section{PENDAHULUAN}

Asma adalah penyakit inflamasi
(radang) kronik saluran napas menyebabkan peningkatan hiperesponsif jalan napas yang menimbulkan gejala episodik berulang berupa mengi/wheeze (napas berbunyi ngik-ngik), sesak napas, dada terasa berat dan batuk-batuk (Dusi, 2009). Bunyi napas wheeze pada paruparu, merupakan salah satu ciri yang menandakan seseorang menderita asma. Pengunaan stetoskop sebagai alat bantu diagnosis cenderung sangat subyektif. Hasil diagnosis dokter sangat tergantung dari kepekaan telinga dan pengalaman yang bersangkutan. Menurut dokter umum yang bertugas di Puskesmas Sikur yakni dr Faried Wajdy mengatakan dengan adanya suatu sistem yang dapat mengenali suara pernapasan pada pasien penderita gangguan pernapasan akan sangat membantu tenaga medis untuk mengenali suara pernapasan, juga selain itu untuk beberapa kasus penyakit kesehatan menular, dokter tidak perlu kontak dengan pasien untuk mendiagnosis penyakit pernapasan.

Dengan adanya suatu sistem yang dapat mengenali suara pernapasan paru pada manusia diharapkan dapat membantu tenaga medis untuk memperoleh hasil yang bersifat objektif. Sehingga peneliti ingin mengkaji suara pernapasan wheeze pada pernapasan asma dan suara pernapasan lainnya. Tujuan penelitian ini yaitu untuk membuat serta menguji suatu sistem yang dapat mengidentifikasi perbedaan ciri suara pernapasan wheeze pada pasien asma dan pernapasan lainnya dengan metode $\mathrm{k}$ Nearest Neighbors. Metode k-NN adalah sebuah metode klasifikasi objek berbasis kedekatan data yang diuji dengan data latih.

\section{KAJIAN PUSTAKA}

Penelitian untuk menganalisis/ mengkaji suara pernapasan manusia telah banyak dilakukan, yang mana pada penelitian tersebut adalah untuk membuktikan bahwa adanya informasi yang dibawa oleh pernapasan tentang apa yang terjadi dalam tubuh manusia. Beberapa penelitian yang telah dilakukan dengan memanfaatkan suara pernapasan adalah untuk membuktikan bahwa subjek memiliki pernapasan normal atau abnormal seperti pada penelitian (Kemalasari, 2016), (Islam, 2018), dan (Kuruma, 2010). Hingga mengkaji karakteristik dari suara pernapasan abnormal (Maulidin, 2018). Namun pada penelitian yang telah dilakukan tersebut, sebagian besar hanya mengkaji pola suara pernapasan saja yang mana data yang didapatkan tersebut tidak dikelompokkan menjadi beberapa kelompok pola pernapasan.

Suara pernapasan paru-paru pada manusia normal (vesikuler) terdengar di semua lapang paru yang normal, bersifat halus, nada rendah, inspirasi lebih panjang dari ekspiasi (Gadge and Rode, 2018). Berikut pada Gambar 1 merupakan gambar pernapasan manusia normal pada penelitian Gadge PB dan Rode SV (2018).

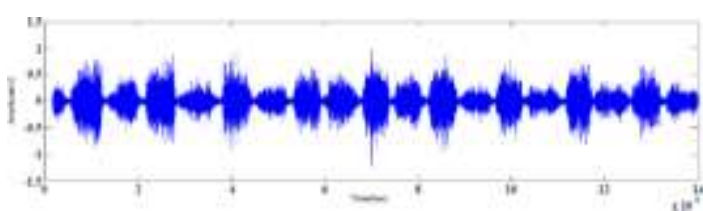

Gambar 1. Pernapasan paru normal dalam domain waktu

Suara pernapasan pada paru-paru penderita asma yakni bersifat kasar, nada tinggi, frekuensi napas yang tinggi, dan terdapat suara mengi atau wheeze (Gadge and Rode, 2018). Berikut pada Gambar 2 merupakan gambar pernapasan manusia penderita asma pada penelitian Gadge PB dan Rode SV (2018).

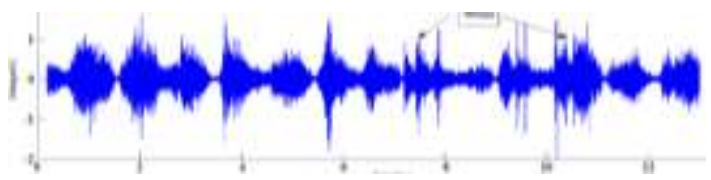

Gambar 2. Pernapasan paru penderita asma dalam domain waktu

\section{a. k-Nearest Neighbors}

k-NN merupakan algoritma yang berfungsi untuk melakukan klasifikasi suatu data berdasarkan data pembelajaran (train data sets), yang diambil dari $\mathrm{k}$ tetangga terdekatnya (nearest neighbors). Dengan k merupakan banyaknya tetangga terdekat. Langkah-langkah untuk menghitung k-NN antara lain:

1. Menentukan parameter $\mathrm{k}$

2. Menghitung jarak anatar data yang akan dievaluasi dengan semua pelatihan

3. Mengurutkan jarak yang terbentuk

4. Menentukan jarak terdekat sampai urutan $\mathrm{k}$ 
5. Memasangkan kelas yang bersesuaian

6. Mencari jumlah kelas dari tetangga yang terdekat dan tetapkan kelas tersebut sebagai kelas data yang akan dievaluasi.

Proses k-NN dilakukan dengan mencari jarak kedekatan nilai antara atribut-atribut data latih dengan data uji. Perhitungan jarak pada proses ini dilakukan dengan menggunakan metode euclidean distance. Berikut rumus pencarian jarak menggunakan rumus Euclidian.

$$
d_{i}=\sqrt{\sum_{i=1}^{p}\left(x_{2 i}-x_{1 i}\right)^{2}}
$$

Dimana $x_{1}, x_{2}, \mathrm{i}, d_{\mathrm{i}}$ dan $p$ adalah sampel data, data uji, variabel data, jarak dan dimensi data.

\section{b. k-Fold Cross Validation}

Cross validation atau dapat disebut juga estimasi rotasi adalah sebuah teknik validasi model untuk mengetahui seberapa akurat sebuah model prediktif ketika dijalankan dalam praktiknya. Salah satu teknik dari validasi silang adalah $\mathrm{k}$-fold cross validation, yang mana memecah data menjadi $\mathrm{k}$ bagian set data dengan ukuran yang sama.

\begin{tabular}{|c|c|c|c|c|c|c|c|c|c|}
\hline 1 & 2 & 3 & 4 & 5 & 6 & 7 & 8 & 9 & 10 \\
\hline 1 & 2 & 3 & 4 & 5 & 6 & 7 & 8 & 9 & 10 \\
\hline & & & & & & & & & \\
\hline 1 & 2 & 3 & 4 & 5 & 6 & 7 & 8 & 9 & 10 \\
\hline 1 & 2 & 3 & 4 & 5 & 6 & 7 & 8 & 9 & 10 \\
\hline 1 & 2 & 3 & 4 & 5 & 6 & 7 & 8 & 9 & 10 \\
\hline 1 & 2 & 3 & 4 & 5 & 6 & 7 & 8 & 9 & 10 \\
\hline 1 & 2 & 3 & 4 & 5 & 6 & 7 & 8 & 9 & 10 \\
\hline 1 & 2 & 3 & 4 & 5 & 6 & 7 & 8 & 9 & 10 \\
\hline 1 & 2 & 3 & 4 & 5 & 6 & 7 & 8 & 9 & 10 \\
\hline 1 & 2 & 3 & 4 & 5 & 6 & 7 & 8 & 9 & 10 \\
\hline & & & \multicolumn{3}{|c|}{ Data Pengujian } & & & & \\
\hline & & & \multicolumn{3}{|c|}{ Data Pelatihan } & & & & \\
\hline
\end{tabular}

Gambar 3. Skema 10 fold cross validation

$\mathrm{k}$-fold cross validation mengulang $\mathrm{k}$ kali untuk membagi sebuah himpunan secara acak menjadi $k$ subset secara bebas, setiap ulangan disisakan satu subset untuk ujian dan subset lainnya untuk pelatihan. Menurut James (2013), pilihan untuk $\mathrm{k}$ biasanya 5 atau 10 , akan tetapi tidak terdapat aturan yang formal. 10 fold $\mathrm{CV}$ adalah salah satu $\mathrm{K}$ fold $\mathrm{CV}$ yang direkomendasikan untuk pemilihan model terbaik karena cenderung memberikan estimasi akurasi yang kurang bias (James, 2013).

\section{METODOLOGI}

Penelitian ini dirancang dalam 5 tahapan utama yaitu (1) pengambilan data suara pada pasien penderita asma dan data suara di internet (2) segmentasi atau pemilihan event pernapasan (3) ekstraksi ciri (4) melakukan training data, serta (5) melakukan testing kemudian menampilkan output. Pembagian ke dalam lima kelompok ini digunakan untuk mengatur alur kerja dari penelitian ini agar lebih spesifik. Tahapan penelitian mengenai suara napas pada penderita asma dan pernapasan tidak asma ini dapat dilihat pada Gambar 4.

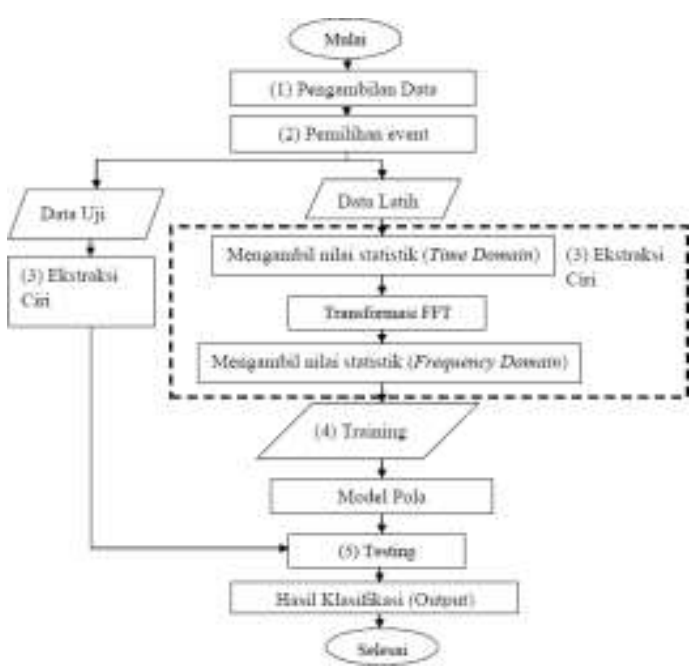

Gambar 4. Diagram alir penelitian

\section{a. Pengambilan Data}

Pengambilan data dilakukan pada subjek hidup di Puskesmas Sikur Lombok Timur dan juga didapatkan melalui website penyedia data suara pernapasan di Internet. Perekaman data suara secara langsung dilakukan menggunakan stetoskop yang telah dimodifikasi sehingga dapat melakukan perekaman napas.

Didesain dengan mengambil bagian chestpiece dan tube dari stetoskop. Kemudian pada bagian ujung tube dihubungkan dengan mikrofon kondenser. Mikrofon kondenser dihubungkan dengan kabel ber-jack $3,5 \mathrm{~mm}$ yang kompatibel 
dengan perangkat komputer. Alat akan bekerja dengan meletakkan chestpiece pada bagian tubuh yang akan diambil suaranya. Chestpiece menangkap sinyal akustik dari suara kemudian disalurkan melalui tube dan ditangkap oleh mikrofon kondenser dan dihubungkan ke soundcard v8 dan kemudian dihubungkan ke laptop.

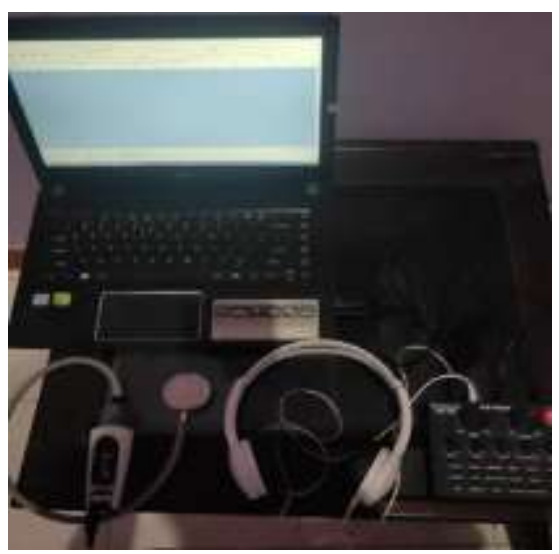

Gambar 5. Alat pengambilan data suara

Perangkat yang digunakan untuk pengambilan data sekunder melalui internet ialah menggunakan laptop atau komputer. Pada tahapan ini, dilakukan proses perekaman suara pernapasan menggunakan software audacity pada website penyedia lung sound atau suara pernapasan paru-paru manusia. Berikut merupakan ilustrasi perekaman suara pernapasan melalui website yang dapat dilihat pada Gambar 6 .

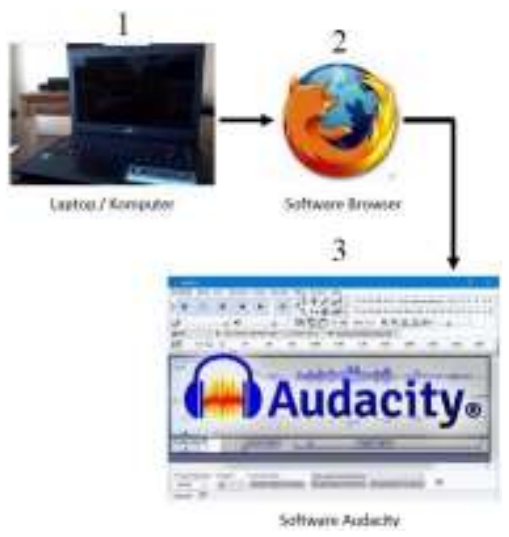

Gambar 6. Perangkat pengambilan data sekunder

\section{b. Preprocessing}

Pada tahapan preprocessing ini, data hasil pengambilan suara baik itu yang diambil secara langsung pada pasien hidup atau yang diambil melalui internet, di process melalui audacity untuk dilakukan proses segmentasi suara pernapasan. Segementasi pernapasan ini dilakukan untuk memotong suara pernapasan ke dalam bebearapa frame kecil agar mudah untuk di proses. Sinyal pernapasan akan dipotong berdasarkan satu putaran pernapasan. Ilustrasi segmentasi sinyal dapat dilihat pada Gambar 7.

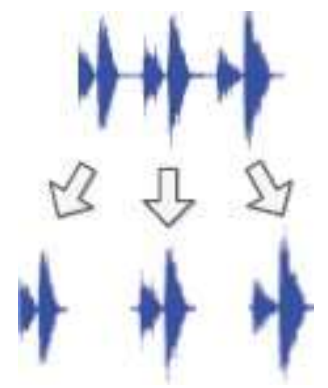

Gambar 7. Ilustrasi segmentasi sinyal

Setelah melakukan segmentasi kemudian menyimpan file data suara kedalam satu folder. Penyimpanan file suara kedalam satu folder dilakukan agar pembacaan file suara dapat dilakukan secara bersamaan sekaligus. File data suara akan disimpan dalam bentuk *.wav dengan nilai kuantisasi 24 bit dan nilai sampling rate $44100 \mathrm{~Hz}$ dengan software audacity.

Kemudian data yang sudah dikumpulkan melalui hasil segmentasi kemudian dilakukan validasi ulang oleh minimal 3 orang tenaga medis untuk membuktikan bahwa data suara yang telah didapatkan adalah benar sesuai dengan data realnya.

\section{c. Ekstraksi Ciri}

Ektraksi ciri data suara merupakan tahap lanjutan untuk mengolah suara pernapasan yang telah didapat. Estraksi ciri data suara dilakukan dengan menggunakan perangkat lunak Octave 5.2. Ekstraksi ciri data suara memiliki 4 tahapan utama yakni (1) Membaca seluruh file wav dalam satu folder, (2) Mengambil nilai statistik data suara dalam domain waktu yakni rata-rata sinyal dan standar deviasi sinyal, (3) Mentransformasi file wav kedalam bentuk domain frekuensi dengan metode Fast Fourier Transform (FFT), (4) Mengambil nilai statistik data suara yang dibutuhkan dalam domain frekuensi diantaranya ratarata spektrum, standar deviasi spektrum, magnitude pada saat frekuensi $\mathrm{OHz}$, Frekuensi dengan magnitude tertinggi pertama, kedua, dan ketiga. Berikut 
merupakan alur pemrosesan ekstraksi ciri data suara dapat dilihat pada Gambar 8.

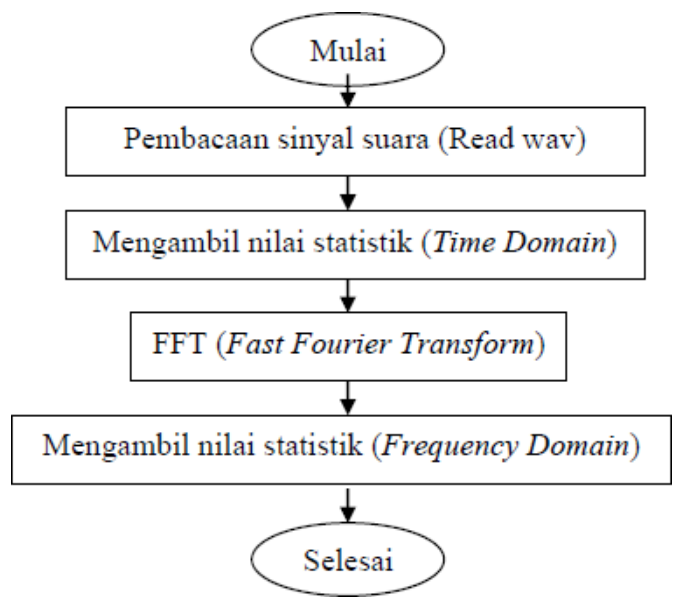

Gambar 8. Alur ekstraksi ciri data suara

\section{d. Training Data}

Pelatihan data diperlukan pada penelitian ini agar sistem dapat mengenali dengan akurat data baru yang masuk ke sistem sehingga dapat memberikan output sistem yang akurat juga. Pada tahap ini terdapat tiga form utama untuk penelitian diantaranya adalah $\mathrm{k}$-fold cross validation, uji akurasi, dan prediksi KNN. Metode k-fold cross validation dan uji akurasi digunakan untuk mengetahui nilai k optimal.

\section{e. Testing}

Uji akurasi ini digunakan untuk mengetahui ketepatan dari nilai $\mathrm{k}$ terbaik yang didapatkan dari proses sebelumnya yaitu k-fold cross validation. Perhitungan pada proses ini ialah dengan membandingkan antara data real dan hasil prediksi menggunakan KNN. Untuk uji akurasi ini data training yang digunakan sebanyak 120 data dan 30 data digunakan sebagai data uji akurasi ketepatan dari nilai $\mathrm{k}$ terbaik dari proses $\mathrm{k}$-fold cross validation. Data uji yang baik untuk digunakan ialah $20 \%$ dengan $80 \%$ sebagai data training (Phil Kim, 2007). Perbandingan ini merupakan perbandingan yang baik untuk meminimalisir terjadinya overfitting yang dapat mempengaruhi rusaknya performance system

\section{HASIL DAN PEMBAHASAN}

\section{a. Perekaman Data Suara}

Pada Tabel 1 ditunjukkan data hasil perekaman suara yang dilakukan pada subjek penderita penyakit asma. Didapatkan 6 data suara pernapasan dari 6 subjek. Durasi perekaman dilakukan berbeda-beda tergantung dari data suara yang dibutuhkan, apabila event suara yang dibutuhkan sudah cukup didapatkan pada satu subjek maka perekaman suara dihentikan, namun apabila event suara yang dibutuhkan dirasa masih kurang maka perekaman suara terus dilakukan hingga dirasa cukup.

Sebelum melakukan perekaman suara pada subjek, tenaga medis menjelaskan pada peneliti bahwa pasien yang akan menjadi subjek penelitian adalah benar menderita asma. Setelah itu peneliti akan meminta izin kepada pasien atau keluarga pasien untuk boleh atau tidaknya dilakukan pengambilan data. Setelah diperbolehkan melakukan pengambilan data, kemudian tenaga medis menjelaskan kepada peneliti bagaimana cara melakukan lung auscultasy yang benar dan dilakukan pengambilan data atau perekaman suara napas. Hasil perekaman suara napas dapat dilihat pada Tabel 1.

Tabel 1. Data suara hasil perekaman

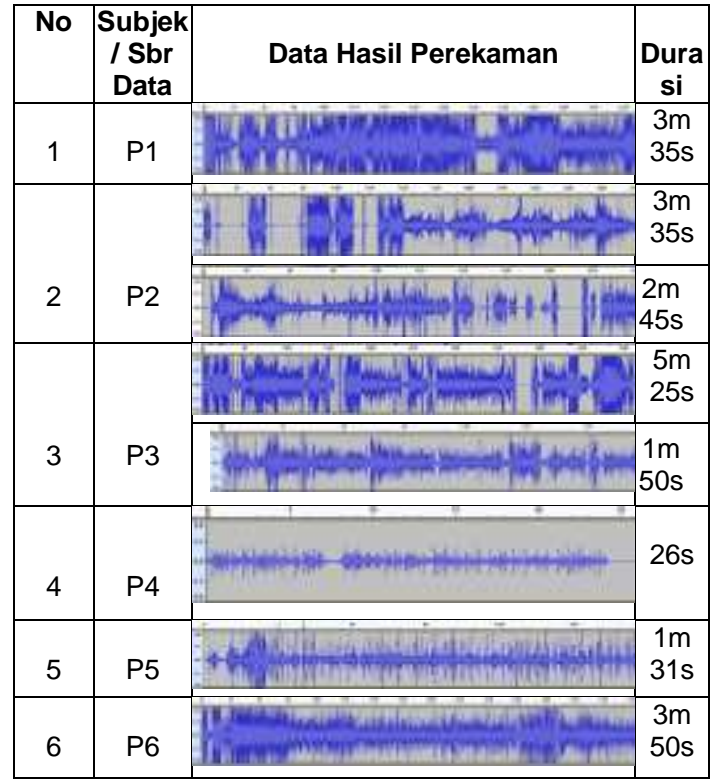

b. Segmentasi Data Suara

Setelah dilakukan segmentasi data suara baik itu data suara hasil perekaman data secara langsung pada subjek penderita asma ataupun data suara yang didapatkan melalui website penyedia data suara pernapasan, kemudian didapatkan total 150 data suara yang mana 75 data suara wheeze dan 75 data suara nonwheeze. 
Tabel 2. Data suara hasil segmentasi

\begin{tabular}{|c|c|}
\hline \multicolumn{2}{|c|}{150 total data suara } \\
\hline Wheeze & 75 data \\
\hline Non-Wheeze & 75 data \\
\hline
\end{tabular}

c. Validasi Data Suara

Data suara hasil perekaman pada subjek di Puskesmas Sikur setelah dilakukan segmentasi kemudian perlu untuk divalidasi atau diperiksa kembali oleh tenaga medis. Hal ini bertujuan untuk mengetahui kebenaran dari data suara hasil perekaman. Pada tahap ini, validasi data suara dilakukan dengan mendengarkan ulang seluruh data suara hasil perekaman pada subjek di Puskesmas Sikur oleh 3 orang tenaga medis. Data suara yang dianalisa oleh tenaga medis ialah data suara wheeze, vesiculer, dan ronchi. Hasil validasi data suara didapatkan oleh ketiga tenaga medis dinyatakan benar.

\section{d. Training Data}

Training data dilakukan dengan 10 fold cross validation dan melakukan k-NN untuk nilai $\mathrm{k}=1, \mathrm{k}=3, \mathrm{k}=5, \mathrm{k}=7, \mathrm{k}=9, \mathrm{k}=11$, $k=13, k=15, k=17, k=19$. Namun sebelum itu, dilakukan pengacakan data.

Tabel 3. Hasil pengacakan data fold cross validation yang mana masingmasing fold menjadi data uji dan kesembilan fold lainnya menjadi data latih. Sehingga hasil latihan sistem ini dapat dilihat pada Gambar 9.

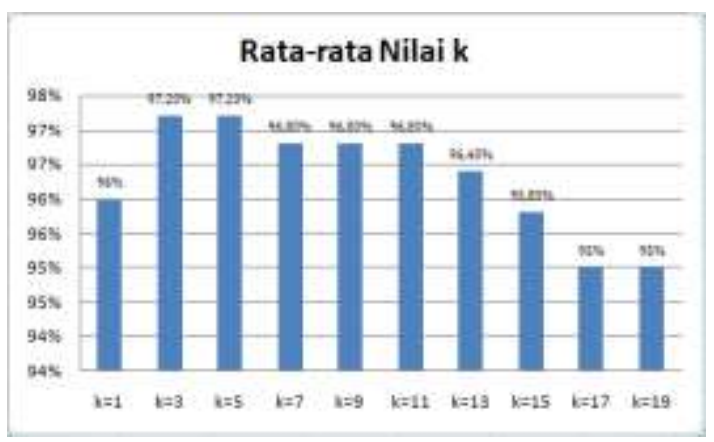

Gambar 9. Rata-rata nilai k hasil k fold CV

Dari Gambar 9 diketahui bahwa nilai rata-rata nilai $\mathrm{k}$ hasil $\mathrm{k}$-fold $\mathrm{CV}$ dengan kemampuan klasifikasi maksimum terdapat pada nilai $\mathrm{k}=3$ dan $\mathrm{k}=5$ dengan rata-rata validitas mencapai $97,2 \%$. Sehingga $k=3$ dan $\mathrm{k}=5$ digunakan untuk pengujian sistem. Dapat diamati juga bahwa semakin besar nilai $\mathrm{k}$ yang digunakan untuk sistem ini, akan membuat semakin kecil pula unjuk kerja dari sistem ini. Namun juga perlu diingat bahwa untuk nilai $\mathrm{k}=1$ memiliki akurasi yang rendah.

\begin{tabular}{|c|c|c|c|c|c|c|c|c|c|}
\hline $\begin{array}{c}\text { Fold } \\
1\end{array}$ & $\begin{array}{c}\text { Fold } \\
2\end{array}$ & $\begin{array}{c}\text { Fold } \\
3\end{array}$ & $\begin{array}{c}\text { Fold } \\
4\end{array}$ & $\begin{array}{c}\text { Fold } \\
5\end{array}$ & $\begin{array}{c}\text { Fold } \\
6\end{array}$ & $\begin{array}{c}\text { Fold } \\
7\end{array}$ & $\begin{array}{c}\text { Fold } \\
8\end{array}$ & $\begin{array}{c}\text { Fold } \\
9\end{array}$ & $\begin{array}{c}\text { Fold } \\
\mathbf{1 0}\end{array}$ \\
\hline $\begin{array}{l}\mathrm{W} \\
(1)\end{array}$ & $\begin{array}{l}W \\
(7)\end{array}$ & $\begin{array}{c}\mathrm{W} \\
(13) \\
\end{array}$ & $\begin{array}{c}W \\
(19)\end{array}$ & $\begin{array}{l}W \\
(25) \\
\end{array}$ & $\begin{array}{l}W \\
(31) \\
\end{array}$ & $\begin{array}{l}\mathrm{W} \\
(37)\end{array}$ & $\begin{array}{l}W \\
(43)\end{array}$ & \begin{tabular}{c|c}
$W$ \\
$(49)$
\end{tabular} & $\begin{array}{l}\text { W Uji coba dilakukan menggunakan } 30 \\
\text { (55) data uji yang sebelumnya belum pernah }\end{array}$ \\
\hline $\begin{array}{l}W \\
(2)\end{array}$ & $\begin{array}{l}\text { W } \\
(8)\end{array}$ & $\begin{array}{c}\mathrm{W} \\
(14)\end{array}$ & $\begin{array}{c}\text { W } \\
(20)\end{array}$ & $\begin{array}{l}\text { W } \\
(26)\end{array}$ & $\begin{array}{c}\text { W } \\
(32)\end{array}$ & $\begin{array}{c}W \\
(38)\end{array}$ & $\begin{array}{c}\mathrm{W} \\
(44)\end{array}$ & $\begin{array}{c}\mathrm{W} \\
(50)\end{array}$ & W digunakan untuk latihan data, da \\
\hline $\begin{array}{l}\text { W } \\
(3) \\
\end{array}$ & $\begin{array}{l}\text { W } \\
(9)\end{array}$ & $\begin{array}{c}\mathrm{W} \\
(15) \\
\end{array}$ & $\begin{array}{c}W \\
(21)\end{array}$ & \begin{tabular}{|c|c|} 
W \\
$(27)$ \\
\end{tabular} & $\begin{array}{c}\text { W } \\
(33)\end{array}$ & $\begin{array}{c}W \\
(39) \\
\end{array}$ & $\begin{array}{c}W \\
(45) \\
\end{array}$ & $\begin{array}{c} \\
(51) \\
\end{array}$ & $\begin{array}{l}\text { W digunakan juuga } 120 \text { data latih yang te } \\
\text { (57) digunakan latihan. } 30 \text { data uji terse }\end{array}$ \\
\hline $\begin{array}{l}\text { W } \\
(4)\end{array}$ & $\begin{array}{c}\mathrm{W} \\
(10)\end{array}$ & $\begin{array}{c}\mathrm{W} \\
(16) \\
\end{array}$ & $\begin{array}{c}W \\
(22) \\
\end{array}$ & \begin{tabular}{|c|c|} 
W \\
$(28)$
\end{tabular} & $\begin{array}{c}\text { W } \\
(34) \\
\end{array}$ & $\begin{array}{c}W \\
(40) \\
\end{array}$ & $\begin{array}{c}W \\
(46)\end{array}$ & $\begin{array}{c}\text { W } \\
(52)\end{array}$ & $\begin{array}{l}\text { W terdiri dari } 15 \text { data pernapasan wheeze d } \\
\text { (58) } 15 \text { pernapasan Non-Wheeze. Dilakuk }\end{array}$ \\
\hline $\begin{array}{l}W \\
(5)\end{array}$ & $\begin{array}{c}\mathrm{W} \\
(11)\end{array}$ & $\begin{array}{c}\mathrm{W} \\
(17)\end{array}$ & $\begin{array}{l}W \\
(23)\end{array}$ & $\begin{array}{c}\mathrm{W} \\
(29)\end{array}$ & $\begin{array}{c}\text { W } \\
(35)\end{array}$ & $\begin{array}{l}W \\
(41)\end{array}$ & $\begin{array}{c}\mathrm{W} \\
(47)\end{array}$ & $\begin{array}{l}W \\
(53)\end{array}$ & (59) dua percobaan yakni pada saat $k=3$ \\
\hline $\begin{array}{l}\text { W } \\
(6)\end{array}$ & $\begin{array}{c}\mathrm{W} \\
(12)\end{array}$ & $\begin{array}{c}\text { W } \\
(18)\end{array}$ & $\begin{array}{l}W \\
(24)\end{array}$ & $\begin{array}{c}\mathrm{W} \\
(30)\end{array}$ & $\begin{array}{c}\text { W } \\
(36)\end{array}$ & $\begin{array}{l}W \\
(42)\end{array}$ & $\begin{array}{c}W \\
(48)\end{array}$ & $\begin{array}{c} \\
(54)\end{array}$ & $\begin{array}{l}\text { W pada saat } \mathrm{k}=5 \text { dikarenakan pada has } \\
\text { (60)pelatihan menggunakan k-fold }\end{array}$ \\
\hline $\begin{array}{l}N W \\
(1)\end{array}$ & $\begin{array}{c}\text { NW } \\
(7)\end{array}$ & $\begin{array}{l}\text { NW } \\
(13)\end{array}$ & $\begin{array}{l}\text { NW } \\
(19)\end{array}$ & $\begin{array}{l}\text { NW } \\
(25)\end{array}$ & $\begin{array}{l}\text { NW } \\
(31)\end{array}$ & $\begin{array}{l}\text { NW } \\
(37)\end{array}$ & $\begin{array}{l}\text { NW } \\
(43)\end{array}$ & $\begin{array}{l}\text { NW } \\
(49)\end{array}$ & $\begin{array}{l}\text { NW didapatkan kedua nilai tersebut ya } \\
\text { (55) menunjukkan hasil paling maksim }\end{array}$ \\
\hline $\begin{array}{c}\text { NW } \\
(2)\end{array}$ & $\begin{array}{l}\text { NW } \\
(8)\end{array}$ & $\begin{array}{l}\text { NW } \\
(14)\end{array}$ & $\begin{array}{l}\text { NW } \\
(20)\end{array}$ & $\begin{array}{l}\text { NW } \\
(26)\end{array}$ & $\begin{array}{l}\text { NW } \\
(32)\end{array}$ & $\begin{array}{l}\text { NW } \\
(38)\end{array}$ & $\begin{array}{l}\mathrm{NW} \\
(44)\end{array}$ & $\begin{array}{l}\text { NW } \\
(50)\end{array}$ & NW diantara k yang lainnya. Kemudian ha \\
\hline $\begin{array}{l}\mathrm{NW} \\
(3)\end{array}$ & $\begin{array}{l}\text { NW } \\
(9)\end{array}$ & $\begin{array}{l}\text { NW } \\
(15)\end{array}$ & $\begin{array}{l}+1 \\
(21)\end{array}$ & \begin{tabular}{|l} 
NW \\
$(27)$ \\
\end{tabular} & $\begin{array}{l}\text { NW } \\
(33)\end{array}$ & $\begin{array}{l}\text { NW } \\
(39)\end{array}$ & $\begin{array}{l}+1 \\
(45)\end{array}$ & \begin{tabular}{|c|} 
NW \\
$(51)$
\end{tabular} & $\begin{array}{l}\text { NW sistem untuk } \mathrm{k}=3 \\
\text { (57)pada Tabel } 4 .\end{array}$ \\
\hline $\begin{array}{c}\text { NW } \\
(4)\end{array}$ & $\begin{array}{l}\text { NW } \\
(10)\end{array}$ & $\begin{array}{l}\text { NW } \\
(16)\end{array}$ & $\begin{array}{l}\text { NW } \\
(22)\end{array}$ & \begin{tabular}{|l|} 
NW \\
$(28)$
\end{tabular} & $\begin{array}{l}\text { NW } \\
\text { (34) }\end{array}$ & $\begin{array}{l}\text { NW } \\
(40)\end{array}$ & $\begin{array}{l}\text { NW } \\
\text { (46) }\end{array}$ & $\begin{array}{l}\text { NW } \\
(52)\end{array}$ & $\begin{array}{l}\text { NW } \\
(58)\end{array}$ \\
\hline $\begin{array}{r}\text { NW } \\
(5)\end{array}$ & $\begin{array}{l}\text { NW } \\
(11)\end{array}$ & $\begin{array}{l}\text { NW } \\
(17)\end{array}$ & $\begin{array}{l}\text { NW } \\
(23)\end{array}$ & \begin{tabular}{|l} 
NW \\
(29)
\end{tabular} & \begin{tabular}{|l} 
NW \\
(35)
\end{tabular} & $\begin{array}{c}\text { NW } \\
(41)\end{array}$ & $\begin{array}{l}\text { NW } \\
(47)\end{array}$ & $\begin{array}{c}\text { NW } \\
(53)\end{array}$ & NW \\
\hline NW & NW & NW & NW & NW & NW & NW & NW & NW & \\
\hline
\end{tabular}

Keterangan:

$$
\begin{array}{ll}
\text { W } & =\text { Wheeze } \\
\text { NW } & =\text { Non-Wheeze }
\end{array}
$$

Setelah melakukan pengacakan data menjadi 10 kelas, selanjutnya melakukan kdata berhasil diklasifikasi dengan benar dan 4 data gagal diklasifikasi dengan benar. Ini menunjukkan performa sistem dapat melakukan klasifikasi data suara menggunakan metode $\mathrm{k}-\mathrm{NN}$ dengan $\mathrm{k}=3$ 
dan $k=5$ adalah sama yakni mencapai $86,6 \%$

Tabel 4. Hasil uji coba sistem

\begin{tabular}{|c|c|c|c|}
\hline \multirow[t]{2}{*}{ Data Uji } & \multirow[t]{2}{*}{ Data real } & \multicolumn{2}{|c|}{ Hasil prediksi k-NN } \\
\hline & & $K=3$ & $\mathrm{~K}=5$ \\
\hline Wheeze (61) & Wheeze & Wheeze & Wheeze \\
\hline Wheeze (62) & Wheeze & Wheeze & Wheeze \\
\hline Wheeze (63) & Wheeze & Wheeze & Wheeze \\
\hline Wheeze (64) & Wheeze & Wheeze & Wheeze \\
\hline Wheeze (65) & Wheeze & Wheeze & Wheeze \\
\hline Wheeze (66) & Wheeze & Wheeze & Wheeze \\
\hline Wheeze (67) & Wheeze & Wheeze & Wheeze \\
\hline Wheeze (68) & Wheeze & Wheeze & Wheeze \\
\hline Wheeze (69) & Wheeze & Wheeze & Wheeze \\
\hline Wheeze (70) & Wheeze & Wheeze & Wheeze \\
\hline Wheeze (71) & Wheeze & Wheeze & Wheeze \\
\hline Wheeze (72) & Wheeze & Wheeze & Wheeze \\
\hline Wheeze (73) & Wheeze & Wheeze & Wheeze \\
\hline Wheeze (74) & Wheeze & Wheeze & Wheeze \\
\hline Wheeze (75) & Wheeze & Wheeze & Wheeze \\
\hline $\begin{array}{c}\text { Non-Wheeze } \\
(61)\end{array}$ & Non-Wheeze & Non-Wheeze & Non-Wheeze \\
\hline $\begin{array}{c}\text { Non-Wheeze } \\
(62)\end{array}$ & Non-l & Non-1 & Non-Wheeze \\
\hline $\begin{array}{c}\text { Non-Wheeze } \\
\text { (63) }\end{array}$ & Non-Wheeze & Non-Wheeze & Non-Wheeze \\
\hline $\begin{array}{c}\text { Non-Wheeze } \\
(64)\end{array}$ & Non-Wheeze & Non-Wheeze & Non-Wheeze \\
\hline $\begin{array}{c}\text { Non-Wheeze } \\
\text { (65) }\end{array}$ & Non-Wheeze & Non-Wheeze & Non-Wheeze \\
\hline $\begin{array}{c}\text { Non-Wheeze } \\
(66)\end{array}$ & Non-Wheeze & Non-Wheeze & Non-Wheeze \\
\hline $\begin{array}{c}\text { Non-Wheeze } \\
(67)\end{array}$ & Non-Wheeze & Wheeze & Wheeze \\
\hline $\begin{array}{c}\text { Non-Wheeze } \\
(68)\end{array}$ & Non-Wheeze & Wheeze & Wheeze \\
\hline $\begin{array}{c}\text { Non-Wheeze } \\
(69)\end{array}$ & Non-Wheeze & Wheeze & Wheeze \\
\hline $\begin{array}{c}\text { Non-Wheeze } \\
(70)\end{array}$ & Non-Wheeze & Wheeze & Wheeze \\
\hline $\begin{array}{c}\text { Non-Wheeze } \\
\text { (71) }\end{array}$ & Non-Wheeze & Non-Wheeze & Non-Wheeze \\
\hline $\begin{array}{c}\text { Non-Wheeze } \\
(72)\end{array}$ & Non-Wheeze & Non-Wheeze & Non-Wheeze \\
\hline $\begin{array}{c}\text { Non-Wheeze } \\
\text { (73) }\end{array}$ & Non-Wheeze & Non-Wheeze & Non-Wheeze \\
\hline $\begin{array}{c}\text { Non-Wheeze } \\
(74)\end{array}$ & Non-Wheeze & Non-Wheeze & Non-Wheeze \\
\hline $\begin{array}{c}\text { Non-Wheeze } \\
(75)\end{array}$ & Non-Wheeze & Non-Wheeze & Non-Wheeze \\
\hline
\end{tabular}

\section{KESIMPULAN}

Berdasarkan penelitian yang dilakukan untuk menguji performa k-NN dalam mengklasifikasikan data suara pernapasan wheeze dan pernapasan nonwheeze dapat ditarik kesimpulan bahwa nilai $\mathrm{k}$ hasil pelatihan menggunakan $\mathrm{k}$-fold CV menunjukkan kemampuan klasifikasi maksimum terdapat pada nilai $\mathrm{k}=3$ dan $\mathrm{k}=5$ dengan kemampuan mencapai $97,2 \%$.
Kinerja k-NN untuk mengenali dan mengklasifikasikan suara pernapasan wheeze pada pasien asma dengan pernapasan selain wheeze untuk $\mathrm{k}=3$ menunjukkan kemampuan $86,6 \%$ dan $\mathrm{k}=5$ juga menunjukkan kemampuan yang sama yakni $86,6 \%$.

\section{REFERENSI}

[1]. Dusi, H., 2009, Warta RSUD dr. H. Soemarno Sosroatmojo Kuala Kapuas No. 4 Tahun III, p. 7-8.

[2]. Kemalasari., Wijayanto, Ardik., and Joko, Pramitra., 2016, Deteksi Kelainan Parenkim Paru Berdasarkan Power Spectra Density Suara Paru Dengan Metode Welch, Jurnal Biomedical Engineering, p. 428-433.

[3]. Islam, Md. Ariful., Bandyopadhyaya, Irin., Bhattacharyya, Parthasarathi., and Saha, Goutam., 2018, Multichannel lung sound analysis for asthma detection, Computer Methods and Programs in Biomedicine, $p$. 2-18.

[4]. Kuruma, Artiarini., Kemalasari., and Wijayanto, Ardik, 2010, Rancang Bangun Deteksi Suara Paru-Paru Dengan Metode Jaringan Syaraf Tiruan Backpropagasi Untuk Mendeteksi Penyakit Asma.

[5]. Maulidin, Lalu Moh. Hasbi., and Amirulloh, Yusuf Aziz., 2018, Analisis Spektral Suara Pernapasan Abnormal Pada Anak-Anak Penderita Pneumonia.

[6]. Gadge, PB., and Rode, SV., 2016, Automatic Wheeze Detection System as Symptoms of Asthma Using Spectral Power Analysis, Journal of Bioengineering and Biomedical Science, Vol. 6, No. 3, p. 1 5.

[7]. James, Gareth., Witten, Daniela., Hastie, Trevor., and Tibshirani, Robert., 2013, An Introduction to Statistical Learning with Applications in R, p. 183- 185.

[8]. Kim, Phil., 2017, Matlab Deep Learning, p. 1-13, Soul-t'ukpyolsi, Seoul, Korea. 